\title{
Eight hours of cold static storage with adenosine and lidocaine (Adenocaine) heart preservation solutions: Toward therapeutic suspended animation
}

\author{
Donna M. Rudd, MSc, and Geoffrey P. Dobson, $\mathrm{PhD}$
}

Objective: Most cardiac preservation solutions provide safe cold ischemic storage times for 4 to 5 hours. Our aim was to investigate the effects of 8 hours of cold static storage $\left(4^{\circ} \mathrm{C}\right)$ using 2 normokalemic, polarizing adenosine-lidocaine (Adenocaine; Hibernation Therapeutics Global Ltd, Kilquade, Ireland) solutions and to compare their functional recovery with hearts preserved in gold standard histidine-tryptophan-ketoglutarate (Custodiol-HTK; Essential Pharma, Newtown, Pa) and Celsior (Genzyme, Cambridge, Mass) solutions.

Methods: Male Sprague-Dawley rats $(350-450 \mathrm{~g})$ were randomly assigned to 1 of 4 groups $(\mathrm{n}=8)$ : $(1)$ adenosine-lidocaine cardioplegia with low $\mathrm{Ca}^{2+} /$ high $\mathrm{Mg}^{2+}$; (2) $2 \times$ adenosine-lidocaine cardioplegia, low $\mathrm{Ca}^{2+} /$ high $\mathrm{Mg}^{2+}$, melatonin, and insulin ( $2 \times$ adenosine, lidocaine, melatonin, and insulin); (3) histidinetryptophan-ketoglutarate solution; or (4) Celsior. Hearts were perfused in working mode, arrested $\left(37^{\circ} \mathrm{C}\right)$, removed, stored for 8 hours at $4^{\circ} \mathrm{C}$, reattached in Langendorff mode and rewarmed for 5 minutes $\left(37^{\circ} \mathrm{C}\right)$, and switched to working mode for 60 minutes. Myocardial oxygen consumption, effluent lactates, and troponin $\mathrm{T}$ levels were measured.

Results: Hearts preserved for 8 hours in adenosine-lidocaine and $2 \times$ adenosine, lidocaine, melatonin, and insulin returned $50 \%$ and $76 \%$ of aortic flow and $70 \%$ and $86 \%$ of coronary flow, respectively, at 60 minutes of reperfusion. In contrast, Custodiol-HTK and Celsior hearts returned $2 \%$ and $17 \%$ of aortic flow and $11 \%$ and $48 \%$ of coronary flow, respectively, at 60 minutes of reperfusion. Hearts preserved in adenosine-lidocaine and $2 \times$ adenosine, lidocaine, melatonin, and insulin returned $90 \%$ and $100 \%$ of developed pressures and $101 \%$ and $104 \%$ of heart rate, respectively. Hearts preserved in histidine-tryptophan-ketoglutarate failed to increase systolic pressure greater than $14 \mathrm{~mm} \mathrm{Hg}$ (11\% baseline) and diastolic pressure greater than $10 \mathrm{~mm} \mathrm{Hg}$ (17\% baseline), and recovered only $16 \%$ of heart rate. Hearts preserved in Celsior developed $70 \%$ of baseline systolic pressures and $86 \%$ recovery of heart rate. At 5 minutes of rewarming after cold storage, the myocardial oxygen consumption for hearts preserved in adenosine-lidocaine, $2 \times$ adenosine, lidocaine, melatonin, and insulin, Custodiol-HTK, and Celsior was $23.0 \pm 5,20 \pm 4,15 \pm 1$, and $10 \pm 2 \mu \mathrm{mol} \mathrm{O}_{2} / \mathrm{min} / \mathrm{g}$ dry wt, respectively, with corresponding lactate outputs of $1.8 \pm 0.8,1.5 \pm 0.7,2.6 \pm 0.7$, and $3.2 \pm 1.4 \mu \mathrm{mol}$ lactate/min/g dry weight. Troponin T was not detected in the coronary effluent of adenosine-lidocaine or $2 \times$ adenosine, lidocaine, melatonin, and insulin hearts, whereas Custodiol-HTK and Celsior hearts had troponin T levels of 0.08 and $0.24 \mu \mathrm{g} / \mathrm{mL}$, respectively.

Conclusions: We report a $78 \%$ return of cardiac output, $90 \%$ to $100 \%$ return of developed pressures, and $101 \%$ to $104 \%$ return of heart rate after 8 hours of cold static storage using normokalemic, adenosine, lidocaine, melatonin, and insulin preservation solution in the isolated rat heart compared with $55 \%$ cardiac output with polarizing adenosine-lidocaine cardioplegia alone, $4 \%$ cardiac output with Custodiol-HTK, and 25\% cardiac output in Celsior preservation solutions. (J Thorac Cardiovasc Surg 2011;142:1552-61)

From a scientific standpoint, depolarizing potassium concentrations of $10 \mathrm{mEq} / \mathrm{L}$ and above in surgical cardioplegia or

From the Heart Research Laboratory, Department of Physiology and Pharmacology, James Cook University, Townsville, Queensland, Australia.

This work was supported by Australian National Health and Medical Research Grant 540409 (to D.R. and G.P.D.).

Disclosures: Authors have nothing to disclose with regard to commercial support.

Received for publication Aug 28, 2010; revisions received April 19, 2011; accepted for publication May 5, 2011; available ahead of print July 11, 2011.

Address for reprints: Geoffrey P. Dobson, PhD, James Cook University, Department of Physiology and Pharmacology, Molecular Science Building, Townsville, Queensland 4811, Australia (E-mail: geoffrey.dobson@jcu.edu.au).

$0022-5223 / \$ 36.00$

Copyright (C) 2011 by The American Association for Thoracic Surgery doi:10.1016/j.jtcvs.2011.05.023 heart preservation solutions may not afford optimal arrest and protection. ${ }^{1}$ In 2004, we introduced a new concept of polarized arrest for surgical cardioplegia using a composition of adenosine and lidocaine (Adenocaine; Hibernation Therapeutics Global Ltd, Kilquade, Ireland) in a physiologic Krebs-Henseleit solution. ${ }^{1,2}$ We reported that Adenocaine in a normokalemic solution arrested the heart by "clamping" the myocyte's diastolic membrane potential at or approximately $-80 \mathrm{mV}$ with an accompanying decrease in myocardial oxygen consumption $\left(\mathrm{MVO}_{2}\right)$ of more than $95 \%$. $^{2}$ The idea was borrowed from natural hibernating animals (or summer estivators) who do not flood their cells with high potassium and depolarize their cell membranes as they 

Abbreviations and Acronyms

$\begin{array}{ll}\mathrm{AF} & =\text { aortic flow } \\ \mathrm{AL} & =\text { adenosine-lidocaine } \\ \mathrm{ALMI} & =\text { adenosine, lidocaine, } \\ & \text { melatonin, and insulin } \\ \text { ANOVA } & =\text { analysis of variance } \\ \mathrm{CF} & =\text { coronary flow } \\ \mathrm{CO} & =\text { cardiac output }\end{array}$
Custodiol-HTK $=$ Custodiol histidine- tryptophan-ketoglutarate
$\mathrm{MVO}_{2}=$ myocardial oxygen consumption
RPP $=$ rate-pressure product

decrease their body's "basal" metabolic rate to pilot-light. ${ }^{3}$ The question posed was "Could the human heart in cardiac surgery be pharmacologically manipulated to operate more like a heart from a natural hibernator?" The early objective was to inhibit the voltage-dependent $\mathrm{Na}^{+}$fast channels responsible for the phase $\mathrm{O}$ upstroke (lidocaine) and simultaneously decrease the action potential duration (open $\mathrm{K}^{+}$ channels) of atria, Purkinje fibers, and ventricles (adenosine), which would theoretically arrest the heart in a more "natural" polarized, diastolic state compared with hyperkalemic depolarized arrest.

The adenosine-lidocaine (AL) polarizing arrest and protection concept has subsequently received proof-of-concept in the canine model of cardiopulmonary bypass ${ }^{4}$ and is used clinically in a number of US centers as Adenocaine allblood microplegia. ${ }^{5}$ In 2008, Jin and colleagues ${ }^{6}$ carried out a 134-patient pediatric safety trial and showed that AL crystalloid "one shot" with moderate hyperkalemia $(10 \mathrm{mmol} / \mathrm{L})$ was more protective than $\mathrm{AL}$ with $20 \mathrm{mmol} / \mathrm{L}$ $\mathrm{K}^{+}$or $20 \mathrm{mmol} / \mathrm{L} \mathrm{K}^{+}$alone. In 2010 , we confirmed the importance of keeping potassium within its normokalemic limits for optimal $\mathrm{AL}$ polarized protection at $32^{\circ} \mathrm{C}$ to $33^{\circ} \mathrm{C}$ in isolated rat hearts and showed that higher (depolarizing) or lower (hyperpolarizing) extracellular potassium arrest resulted in significantly higher coronary vascular resistances, slower times to first beat (stunning), and lower cardiac outputs (COs) with lower contractility. ${ }^{1,7}$

AL cardioplegia also appears versatile as a preservation solution at both cold static storage $\left(4^{\circ} \mathrm{C}\right)$ and warmer intermittent perfusion $\left(28^{\circ} \mathrm{C}-30^{\circ} \mathrm{C}\right)$ compared with Celsior (Genzyme, Cambridge, Mass). ${ }^{8}$ In 2011, we reported that reperfusing the isolated rat heart for 5 minutes with warm, oxygenated polarizing AL arrest after 6 hours of cold storage in AL cardioplegia or Celsior led to significantly higher recoveries and may offer a new paradigm of polarizing protection for rewarming and implantation. ${ }^{9}$ The aim of the present study is to investigate the effects of 8 hours of cold static storage $\left(4^{\circ} \mathrm{C}\right)$ using 2 modified $\mathrm{AL}$ (Adenocaine) preservation solutions and compare them with Custodiol histidine-tryptophan-ketoglutarate (Custodiol-HTK; Essential Pharma, Newtown, Pa) and Celsior solutions.

\section{MATERIALS AND METHODS \\ Animals}

Male Sprague-Dawley rats (350-450 g, $\mathrm{n}=40)$ were obtained from James Cook University's breeding colony. Animals were fed ad libitum and housed in 10/14 hour light/dark cycle. On the day of experiment, rats were anesthetized with an intraperitoneal injection of thiopentone sodium (Thiobarb; $60 \mathrm{mg} / \mathrm{kg}$ body wt [Lyppard, Queensland, Australia]), and the hearts were rapidly excised as described by Dobson and Jones. ${ }^{2}$ Rats were handled in compliance with James Cook University Guidelines (ethics approval numbers A1084 and A1515) and the "Guide for Care and use of Laboratory Animals" from the National Institutes of Health (Publication No. 85-23, revised 1985, and PHS Publication 1996). Adenosine (A9251 $>99 \%$ purity), histidine, histidine- $\mathrm{HCl}$, tryptophan, alpha-ketoglutarate, mannitol, and melatonin (N-acetyl-5-methoxytryptamine) were obtained from Sigma Chemical Company (Castle Hill, NSW, Australia). Lidocaine hydrochloride ( $2 \%$ solution, ilium) and insulin $(40 \mathrm{IU} / \mathrm{mL})$ were obtained from Lyppard (Queensland, Australia). Celsior was purchased as a Food and Drug Administration-approved product from Clifford Hallam Healthcare (Agent for Genzyme, North Ryde, NSW, Australia).

\section{Arrest Solutions for Normothermic Induction and Cold Static Storage} Adenosine-lidocaine solution with low $\mathrm{Ca}^{2+} / \mathrm{high}_{\mathrm{Mg}^{2+}}$. The AL cardioplegia contained $200 \mu \mathrm{mol} / \mathrm{L}$ adenosine plus $500 \mu \mathrm{mol} / \mathrm{L} \mathrm{li}$ docaine in $10 \mathrm{mmol} / \mathrm{L}$ glucose containing modified Krebs-Henseleit buffer ( $\mathrm{pH} 7.7$ at $37^{\circ} \mathrm{C}$ ) with low $\mathrm{Ca}^{2+} /$ high $\mathrm{Mg}^{2}\left(0.22 \mathrm{mmol} / \mathrm{L} \mathrm{CaCl}_{2}\right.$ and 2.6 $\mathrm{mmol} / \mathrm{L} \mathrm{MgCl}_{2}$ ). The solution was filtered using $0.2-\mu \mathrm{m}$ filters and maintained at $37^{\circ} \mathrm{C}$. These AL concentrations have been used in previous cardioplegia and preservation studies. ${ }^{8,9}$ The arrest solution was not actively bubbled with $95 \% \mathrm{O}_{2} / 5 \% \mathrm{CO}_{2}$, thus the higher $\mathrm{pH}$. The average $\mathrm{Po}_{2}$ of the AL solution at the beginning of storage was $140 \mathrm{~mm} \mathrm{Hg}$ and the $\mathrm{PCO}_{2}$ was 5 to $10 \mathrm{~mm} \mathrm{Hg}$.

$2 \times$ adenosine-lidocaine solution with low $\mathrm{Ca}^{2+} / \mathbf{h i g h}$ $\mathbf{M g}^{2+}$, melatonin, and insulin. The composition was the same as the AL solution (above) with the following additions: twice the concentration of A and $\mathrm{L}(400 \mu \mathrm{mol} / \mathrm{L}$ and $1000 \mu \mathrm{mol} / \mathrm{L}), 100 \mu \mathrm{mol} / \mathrm{L}$ melatonin, and $0.01 \mathrm{IU} / \mathrm{mL}$ insulin. The reason for doubling $\mathrm{AL}$ was from previous 6-hour cold static storage studies that showed a moderate but significant 1.3-fold increase in left ventricular function (aortic flow [AF] $)$ and improved electrical stability $(n=6$; D.M.R. and G.P.D. unpublished data, 2010). Higher AL concentrations may also improve protection because lidocaine is known to have a reduced ability to block sodium fast channels at lower temperatures ${ }^{10}$ (and perhaps the same exists for adenosine and adenosine receptors). The naturally occurring pineal gland hormone melatonin was chosen because it is a free radical scavenger (5 times more effective in neutralizing $\mathrm{OH}^{-}$radicals than glutathione) and is a powerful antioxidant with cardioprotective properties. ${ }^{11}$ Insulin was chosen because of its antioxidant and cardioprotective properties (see "Discussion"). ${ }^{12}$ Preliminary experiments showed that melatonin and insulin added to AL arrest solution, singly or in combination, improved functional recoveries after 6 hours of cold static storage. The concentrations of each drug were chosen from their cardioprotective properties in the isolated perfused heart. ${ }^{1,12}$

Celsior solution. The Celsior solution contained $100 \mathrm{mmol} / \mathrm{L} \mathrm{NaOH}$, $15 \mathrm{mmol} / \mathrm{L} \mathrm{KCl}, 13 \mathrm{mmol} / \mathrm{L} \mathrm{MgCl}_{2}, 0.25 \mathrm{mmol} / \mathrm{L} \mathrm{CaCl} \mathrm{Ca}_{2}, 20 \mathrm{mmol} / \mathrm{L}$ glutamic acid, $80 \mathrm{mmol} / \mathrm{L}$ lactobionic acid, $30 \mathrm{mmol} / \mathrm{L}$ histidine, and 3 
$\mathrm{mmol} / \mathrm{L}$ glutathione. The solution was used as supplied from Genzyme with no modification. The solution was filtered with a $0.2-\mu \mathrm{mol} / \mathrm{L}$ filter, was not actively bubbled with $95 \% \mathrm{O}_{2} / 5 \% \mathrm{CO}_{2}$, and had an average $\mathrm{Po}_{2}$ of $149 \mathrm{~mm} / \mathrm{Hg}$. Custodiol histidine-tryptophan-ketoglutarate solution. The Custodiol-HTK solution contained $15 \mathrm{mmol} / \mathrm{L} \mathrm{NaCl}, 9 \mathrm{mmol} / \mathrm{L}$ $\mathrm{KCl}, 4.0 \mathrm{mmol} / \mathrm{L} \mathrm{MgCl}_{2}, 0.015 \mathrm{mmol} / \mathrm{L} \mathrm{CaCl} 2,1.0 \mathrm{mmol} / \mathrm{L}$ alphaketoglutarate, $180 \mathrm{mmol} / \mathrm{L}$ histidine, $18 \mathrm{mmol} / \mathrm{L}$ histidine- $\mathrm{HCl}, 30$ $\mathrm{mmol} / \mathrm{L}$ mannitol, and $2 \mathrm{mmol} / \mathrm{L}$ tryptophan. ${ }^{13,14}$

\section{Arrest Solutions for 5 Minutes of Warm Reperfusion After Cold Static Storage}

The AL and ALMI, Celsior, and Custodiol-HTK arrest solutions were the same as described above except they were actively bubbled with $95 \% \mathrm{O}_{2} / 5 \% \mathrm{CO}_{2}$ to achieve a $\mathrm{Po}_{2}$ greater than $600 \mathrm{~mm} \mathrm{Hg}$, and the solutions were not recirculated.

\section{Composition of Modified Krebs-Henseleit for Reperfusion in Working Mode}

The modified Krebs-Henseleit buffer contained $10 \mathrm{mmol} / \mathrm{L}$ glucose, $117 \mathrm{mmol} / \mathrm{L} \mathrm{NaCl}, 5.9 \mathrm{mmol} / \mathrm{L} \mathrm{KCl}, 25 \mathrm{mmol} / \mathrm{L} \mathrm{NaHCO}_{3}, 1.2 \mathrm{mmol} / \mathrm{L}$ $\mathrm{NaH}_{2} \mathrm{PO}_{4}, 1.12 \mathrm{mmol} / \mathrm{L} \mathrm{CaCl}$ (free $\mathrm{Ca}^{2+}=1.07 \mathrm{mmol} / \mathrm{L}$ ), and 0.512 $\mathrm{mmol} / \mathrm{L} \mathrm{MgCl}_{2}$ (free $\mathrm{Mg}^{2+}=0.5 \mathrm{mmol} / \mathrm{L}$ ), $\mathrm{pH} 7.4$ at $37^{\circ} \mathrm{C}$. The perfusion buffer was filtered using a $1-\mu \mathrm{mol} / \mathrm{L}$ membrane and then bubbled vigorously with $95 \% \mathrm{O}_{2} / 5 \% \mathrm{CO}_{2}$ to achieve a $\mathrm{Po}_{2}$ greater than $600 \mathrm{~mm} \mathrm{Hg}$. The perfusion buffer was not recirculated.

\section{Experimental Groups}

Rats were randomly assigned to 1 of 4 groups ( $n=8$ each group): (1) AL cardioplegia; (2) $2 \times$ AL cardioplegia with low $\mathrm{Ca}^{2+} / \mathrm{high}^{2+}$, melatonin, and insulin; (3) Celsior; or (4) Custodiol-HTK solution.

Langendorff and working rat heart preparation. Hearts were rapidly removed from anesthetized rats and placed in ice-cold, heparinized, modified Krebs-Henseleit buffer (Figure 1). The details of heart preparation, surgical attachment, and perfusion have been described by
Rudd and Dobson. ${ }^{89}$ Briefly, hearts were attached to a Langendorff apparatus and perfused at a pressure head of $90 \mathrm{~cm} \mathrm{H}_{2} \mathrm{O}(68 \mathrm{~mm} \mathrm{Hg})$. The pulmonary artery was not cannulated before arrest, and the heart was detached for 8 hours of cold static storage to prevent vessel wall damage. The heart was cannulated after cold storage for collection of coronary venous effluent and $\mathrm{O}_{2}$ consumption measurements. For working mode operation, a small incision was made in the left atrial appendage and a cannula was inserted and sutured, which was switched from the aorta to the left atrial cannula at a hydrostatic pressure of $10 \mathrm{~cm}$ $\mathrm{H}_{2} \mathrm{O}$ (preload) and an afterload pressure of $100 \mathrm{~cm} \mathrm{H} \mathrm{H}_{2} \mathrm{O}(76 \mathrm{~mm} \mathrm{Hg}$ ). Heart rate, aortic pressure, coronary flow, and $\mathrm{AF}$ were measured before and after 8 hours of cold static storage (Figure 1). CO was the sum of aortic and coronary flows. During the 15 -minute equilibration period, the initial criteria for exclusion of working hearts were a heart rate less than 200 beats/min, systolic pressure less than $100 \mathrm{~mm} \mathrm{Hg}$, and coronary flow less than $10 \mathrm{~mL} / \mathrm{min}$.

\section{Cold Static Storage $\left(4^{\circ} \mathrm{C}\right)$ and Early Reperfusion}

The method of cold static storage for rat hearts has been described by Rudd and Dobson. ${ }^{8,9}$ Briefly, hearts were arrested at a constant pressure head of $90 \mathrm{~cm} \mathrm{H} \mathrm{H}_{2} \mathrm{O}(68 \mathrm{~mm} \mathrm{Hg})$ using $\mathrm{AL}$ cardioplegia or Celsior solution for 5 minutes $(50-100 \mathrm{~mL})$ at $37^{\circ} \mathrm{C}$ for their respective groups. Hearts were gently removed from the apparatus and placed in a $50-\mathrm{mL}$ tube containing their respective air-equilibrated preservation solutions, and the sealed tube was immersed in the water bath at $4^{\circ} \mathrm{C}$ for 8 hours (Figure 1). After 8 hours of storage, the hearts were immediately reattached to the perfusion apparatus, and fresh, warm oxygenated arrest solutions (AL, $2 \times$ ALMI, Custodiol-HTK, or Celsior) were used to reperfuse the heart in nonworking Langendorff mode at a pressure head of $90 \mathrm{~cm} \mathrm{H}_{2} \mathrm{O}$ $(68 \mathrm{~mm} \mathrm{Hg}$ ) for 5 minutes (Figure 1). The heart's surface temperature was $28^{\circ} \mathrm{C}$ to $32^{\circ} \mathrm{C}^{9}$ Temperature was measured using a Cole-Palmer thermistor-thermometer (8402-20; John Morris Scientific, Bowen Hills, Queensland, Australia), which was tucked under the left auricle. Hearts were then switched to working mode and reperfused for 60 minutes at $37^{\circ} \mathrm{C}$ using oxygenated glucose containing Krebs-Henseleit $\mathrm{pH}$ 7.4. Hearts were allowed to spontaneously return to function during reperfusion, and

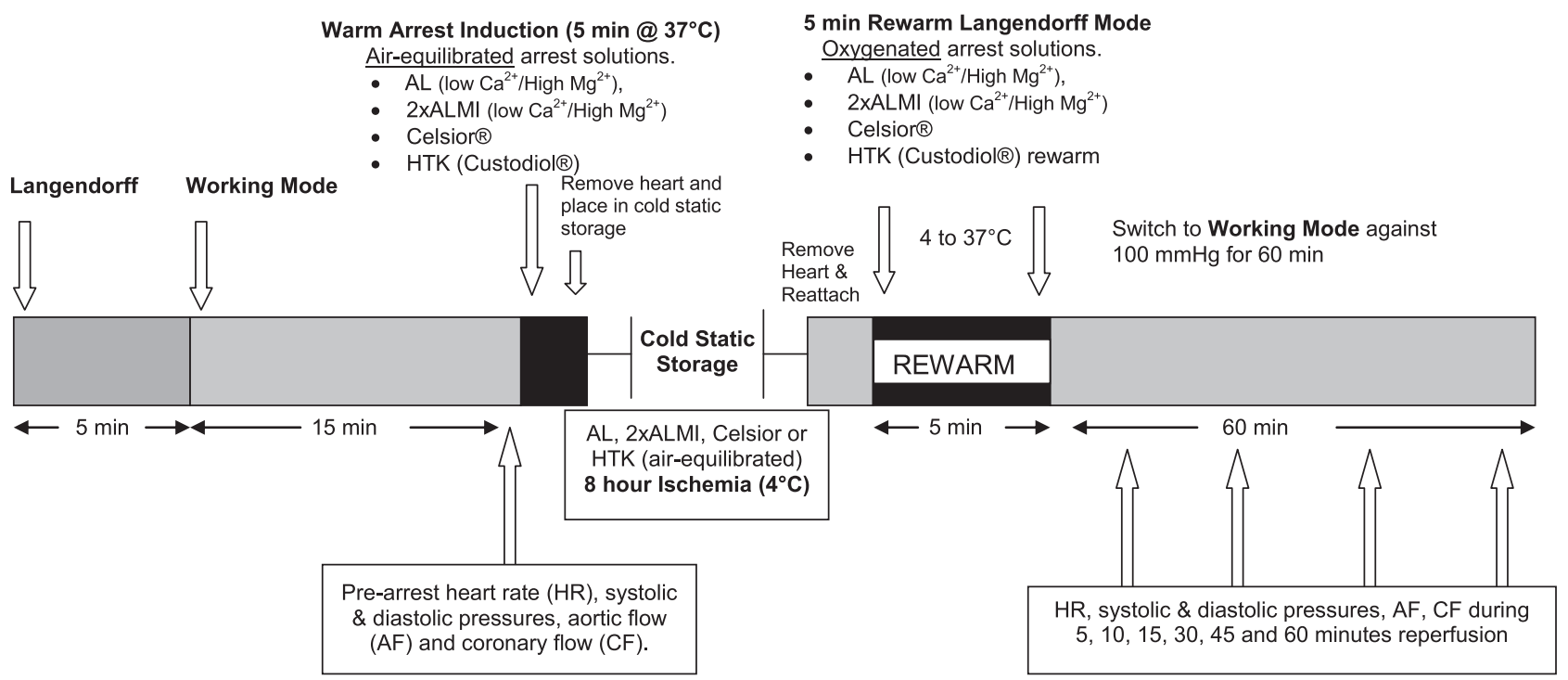

FIGURE 1. Experimental protocol. Isolated rat hearts were placed in cold static storage for 8 hours in (1) AL polarizing cardioplegia with low $\mathrm{Ca}^{2+} / \mathrm{high}$ $\mathrm{Mg}^{2+}(0.22 \mathrm{mmol} / \mathrm{L} / 2.6 \mathrm{mmol} / \mathrm{L})$; (2) AL doubled in concentration with melatonin (100 $\mu$ mol/L) and insulin (0.01 IU/mL) (2× ALMI); (3) Custodiol-HTK; and (4) Celsior depolarizing preservation solutions. Each group was rewarmed in Langendorff mode for 5 minutes with their respective oxygenated arrest solution (see "Materials and Methods" for details). AL, Adenosine-lidocaine; $A L M I$, adenosine, lidocaine, melatonin, and insulin; HTK, Custodiol histidinetryptophan-ketoglutarate. 
they were not electrically assisted if function did not return. Functional data (aortic and coronary flow, heart rate, and systolic and diastolic pressures) were measured at $5,10,15,30,45$, and 60 minutes during the 60 -minute reperfusion. These data were compared with the baseline (prearrest) data for each group. Myocardial oxygen consumption $\left(\mu \mathrm{mole} \mathrm{O}_{2} / \mathrm{min} / \mathrm{g}\right.$ dry wt heart) was calculated using equations and methods described by Dobson and Jones ${ }^{2}$ and Rudd and Dobson. ${ }^{8,9}$ Coronary venous effluent was measured in milliliters/minute, and heart weight was expressed as grams of dry weight. Total tissue water $(\%)$ was determined by the difference in wet weight and dry weight divided by wet weight and multiplied by 100 .

\section{Lactate Output and Troponin $\mathrm{T}$ Release at 5 Minutes Warm Reperfusion}

Coronary effluent (1.0-1.5 mL) was collected in small 1.5-m Eppendorf tubes during the last minute of the rewarming period and stored at $-20^{\circ} \mathrm{C}$ until analysis ( $\sim 2$ weeks). Perfusate lactates were analyzed on Cobas Integra 800 using a colorimetric kit purchased from Roche Diagnostics, Brisbane, Queensland, Australia. Output results were in millimoles/liter and converted to micromoles/minute/gram dry weight using coronary flow $(\mathrm{CF})$ and heart weight as in equation (1):

$$
\begin{aligned}
\text { Lactate }(\mu \mathrm{mol} / \mathrm{min} / \mathrm{g} \text { dry wt })= & \text { Lactate }(\mu \mathrm{mol} / \mathrm{mL}) \times \mathrm{CF}(\mathrm{mL} / \mathrm{min}) \\
& \times 1 / \text { heart weight }(\mathrm{g} \text { dry wt })^{-1}
\end{aligned}
$$

Troponin T was measured on fresh effluent using the enzyme immunoassay method of the Roche Cardiac T Quantitative test on the Roche Cardiac Reader System (Roche Diagnostics). The method has a lower limit of detection of approximately $0.03 \mu \mathrm{g} / \mathrm{L}$. Broad clinical prognostic values for troponin $\mathrm{T}$ reference range are as follows: no myocardial damage,
$0.0-0.05 \mu \mathrm{g} / \mathrm{L}$; myocardial damage possible, $0.05-0.1 \mu \mathrm{g} / \mathrm{L}$; myocardial damage detected, greater than $0.1 \mu \mathrm{g} / \mathrm{L} .{ }^{15}$

\section{Statistical Analysis}

All results are expressed as mean \pm standard error of the mean. Oneway analysis of variance (ANOVA) was used to compare rat weights, arrest times, and time to first beat and AF. Two-way ANOVA with repeated measures was used to compare recovery variables (eg, $\mathrm{AF}$, systolic and diastolic pressures, heart rate, $\mathrm{CO}$ ) over multiple time points for the different treatment groups. One-way ANOVA was used to compare recovery of variables at specific times points $(5,10,30,45$, and 60 minutes) during reperfusion in working mode. Significance was then assessed using Bonferroni and Dunnet 2-way post hoc tests.

\section{RESULTS}

Heart functional properties before and after cold static storage in the 4 different preservation solutions are shown in Table 1 and Figures 2 and 3. During prearrest, there were no significant differences among the groups in $\mathrm{AF}$, $\mathrm{CF}, \mathrm{CO}$, heart rate, developed pressures, or rate-pressure product (RPP) (Table 1).

\section{Recovery of Aortic Flow, Coronary Flow, and Cardiac Output}

Baseline values of $\mathrm{AF}$ ranged from 54 to $63 \mathrm{~mL} / \mathrm{min}^{-1}$. Five minutes after switching to working mode, the

TABLE 1. Functional parameters of isolated working rat hearts after 8-hour cold static ischemic storage $\left(4^{\circ} \mathrm{C}\right)$ and 5 -minute oxygenated rewarming in polarizing adenosine-lidocaine and $2 \times$ adenosine, lidocaine, melatonin, and insulin solutions or depolarizing Custodiol-HTK and

\begin{tabular}{|c|c|c|c|c|c|c|c|c|c|c|c|c|c|}
\hline \multirow[b]{2}{*}{ Time } & \multirow{2}{*}{$\begin{array}{l}\text { Cold arrest } \\
\text { + rewarm } \\
\text { treatment } \\
\end{array}$} & \multirow[b]{2}{*}{$\mathbf{n}$} & \multicolumn{2}{|c|}{$\begin{array}{c}\text { Aortic flow } \\
(\mathrm{mL} / \mathrm{min})\end{array}$} & \multicolumn{2}{|c|}{$\begin{array}{c}\text { Coronary flow } \\
(\mathrm{mL} / \mathrm{min}) \\
\end{array}$} & \multicolumn{2}{|c|}{$\begin{array}{c}\text { Cardiac output } \\
(\mathrm{mL} / \mathrm{min}) \\
\end{array}$} & \multicolumn{2}{|c|}{$\begin{array}{l}\text { Heart rate } \\
\text { (beats/min) }\end{array}$} & \multirow{2}{*}{$\begin{array}{l}\text { Systolic } \\
\text { pressure } \\
(\mathbf{m m ~ H g})\end{array}$} & \multirow{2}{*}{$\begin{array}{l}\text { Diastolic } \\
\text { pressure } \\
(\mathrm{mm} \mathrm{Hg})\end{array}$} & \multirow{2}{*}{$\begin{array}{c}\text { Rate-pressure } \\
\text { product } \\
\text { (beats/mm Hg/min) }\end{array}$} \\
\hline & & & Value & $\% \mathbf{P A}$ & Value & $\% \mathbf{P A}$ & Value & $\% \mathbf{P A}$ & Value & $\% \mathbf{P A}$ & & & \\
\hline \multirow{4}{*}{$\begin{array}{l}15 \text { min } \\
\text { prearrest }\end{array}$} & $\mathrm{AL}$ & 8 & $60 \pm 2$ & & $20 \pm 1$ & & $80 \pm 2$ & & $280 \pm 7$ & & $124 \pm 2$ & $60 \pm 0$ & $34,561 \pm 584$ \\
\hline & $2 \times \mathrm{ALMI}$ & 8 & $62 \pm 1$ & & $22 \pm 1$ & & $85 \pm 2$ & & $303 \pm 7$ & & $128 \pm 1$ & $60 \pm 0$ & $38,836 \pm 957$ \\
\hline & HTK & 8 & $54 \pm 2$ & & $19 \pm 1$ & & $73 \pm 2$ & & $275 \pm 8$ & & $125 \pm 1$ & $60 \pm 0$ & $34,404 \pm 943$ \\
\hline & Celsior & 8 & $63 \pm 4$ & & $21 \pm 2$ & & $85 \pm 5$ & & $286 \pm 12$ & & $126 \pm 2$ & $60 \pm 0$ & $36,041 \pm 1268$ \\
\hline \multirow{4}{*}{$\begin{array}{l}\text { 5-min } \\
\text { recovery }\end{array}$} & AL & 8 & $0 \pm 0$ & 0 & $1 \pm 1$ & 1 & $1 \pm 1$ & 1 & $4 \pm 4$ & 1 & $3 \pm 3$ & $1 \pm 1$ & $80 \pm 80$ \\
\hline & $2 \times$ ALMI & 8 & $3 \pm 3$ & 1 & $2 \pm 2$ & 9 & $5 \pm 5$ & 6 & $25 \pm 25$ & 8 & $16 \pm 16$ & $8 \pm 8$ & $3250 \pm 3250$ \\
\hline & HTK & 8 & $0 \pm 0$ & 0 & $1 \pm 1$ & 5 & $1 \pm 1$ & 1 & $22 \pm 7$ & 8 & $14 \pm 5$ & $9 \pm 3$ & $446 \pm 201$ \\
\hline & Celsior & 8 & $0 \pm 0$ & 0 & $3 \pm 2$ & 14 & $3 \pm 2$ & 4 & $48 \pm 13$ & 17 & $31 \pm 9$ & $19 \pm 3$ & $1998 \pm 935$ \\
\hline \multirow{4}{*}{$\begin{array}{l}\text { 10-min } \\
\text { recovery }\end{array}$} & $\mathrm{AL}$ & 8 & $11 \pm 6$ & 18 & $11 \pm 3$ & 55 & $22 \pm 9$ & 28 & $139 \pm 44$ & 50 & $71 \pm 17$ & $40 \pm 10$ & $14,673 \pm 5320$ \\
\hline & $2 \times$ ALMI & 8 & $14 \pm 7$ & 22 & $8 \pm 4$ & 36 & $22 \pm 11$ & 26 & $118 \pm 50$ & 39 & $51 \pm 20$ & $25 \pm 10$ & $13,078 \pm 6316$ \\
\hline & HTK & 8 & $0 \pm 0$ & 0 & $2 \pm 1$ & 11 & $2 \pm 1$ & 3 & $39 \pm 21$ & 14 & $15 \pm 9$ & $10 \pm 5$ & $1795 \pm 1377$ \\
\hline & Celsior & 8 & $1 \pm 1$ & 2 & $8 \pm 2$ & 38 & $9 \pm 3$ & 11 & $176 \pm 39$ & 62 & $66 \pm 10$ & $48 \pm 8$ & $13,944 \pm 3680$ \\
\hline \multirow{4}{*}{$\begin{array}{l}\text { 30-min } \\
\text { recovery }\end{array}$} & $\mathrm{AL}$ & 8 & $28 \pm 5 \dagger$ & 47 & $15 \pm 2 \dagger$ & 75 & $43 \pm 1$ & 54 & $293 \pm 22$ & 105 & $110 \pm 3$ & $63 \pm 2$ & $32,155 \pm 2515$ \\
\hline & $2 \times$ ALMI & 8 & $44 \pm 2 *$ & 71 & $18 \pm 1 \ddagger, \S$ & 82 & $62 \pm 3 \ddagger, \S$ & 73 & $294 \pm 16 \S$ & 97 & $121 \pm 3 \ddagger, \S$ & $60 \pm 0 \S$ & $35,294 \pm 1496 \ddagger, \S$ \\
\hline & HTK & 8 & $0 \pm 0$ & 0 & $2 \pm 1$ & 11 & $2 \pm 1$ & 3 & $41 \pm 27$ & 15 & $13 \pm 11$ & $10 \pm 9$ & $2411 \pm 2221$ \\
\hline & Celsior & 8 & $8 \pm 4$ & 13 & $10 \pm 2 \|$ & 48 & $18 \pm 6$ & 21 & $213 \pm 32 \|$ & $75 \|$ & $88 \pm 8 \|$ & $59 \pm 5 \|$ & $19,998 \pm 3834 \|$ \\
\hline \multirow{4}{*}{$\begin{array}{l}\text { 60-min } \\
\text { recovery }\end{array}$} & $\mathrm{AL}$ & 8 & $30 \pm 5 \dagger$ & 50 & $14 \pm 2 \dagger$ & 70 & $44 \pm 6 \dagger$ & 55 & $283 \pm 19$ & 101 & $111 \pm 3$ & $63 \pm 2$ & $31,518 \pm 2346$ \\
\hline & $2 \times \mathrm{ALMI}$ & 8 & $47 \pm 3^{*}$ & 76 & $19 \pm 1 \ddagger, \S$ & 86 & $66 \pm 3 \ddagger, \S$ & 78 & $314 \pm 12 \S$ & 104 & $117 \pm 3 \S$ & $60 \pm 0 \S$ & $36,800 \pm 1021 \ddagger, \S$ \\
\hline & HTK & 8 & $1 \pm 1$ & 2 & $2 \pm 1$ & 11 & $3 \pm 2$ & 4 & $44 \pm 30$ & 16 & $14 \pm 12$ & $10 \pm 9$ & $3396 \pm 2781$ \\
\hline & Celsior & 8 & $11 \pm 5$ & 17 & $10 \pm 2 \|$ & 48 & $21 \pm 7$ & 25 & $247 \pm 28 \|$ & $86 \|$ & $89 \pm 6 \|$ & $62 \pm 4 \|$ & $21,473 \pm 3642 \|$ \\
\hline
\end{tabular}
Celsior solutions

See "Materials and Methods" for details. No significant differences between prearrest groups. $A L$, Adenosine-lidocaine; $A L M I$, adenosine, lidocaine, melatonin, and insulin; HTK, Custodiol histidine-tryptophan-ketoglutarate. *ALMI significantly different from all other groups, $P<.05$. $\dagger$ AL significantly different from Custodiol-HTK or Celsior or both, $P<.05$. ‡ALMI significantly different from Celsior only, $P<.05$. §ALMI significantly different from Custodiol-HTK only, $P<.05$. $\|$ Celsior significantly different from Custodiol-HTK, $P<.05$. 

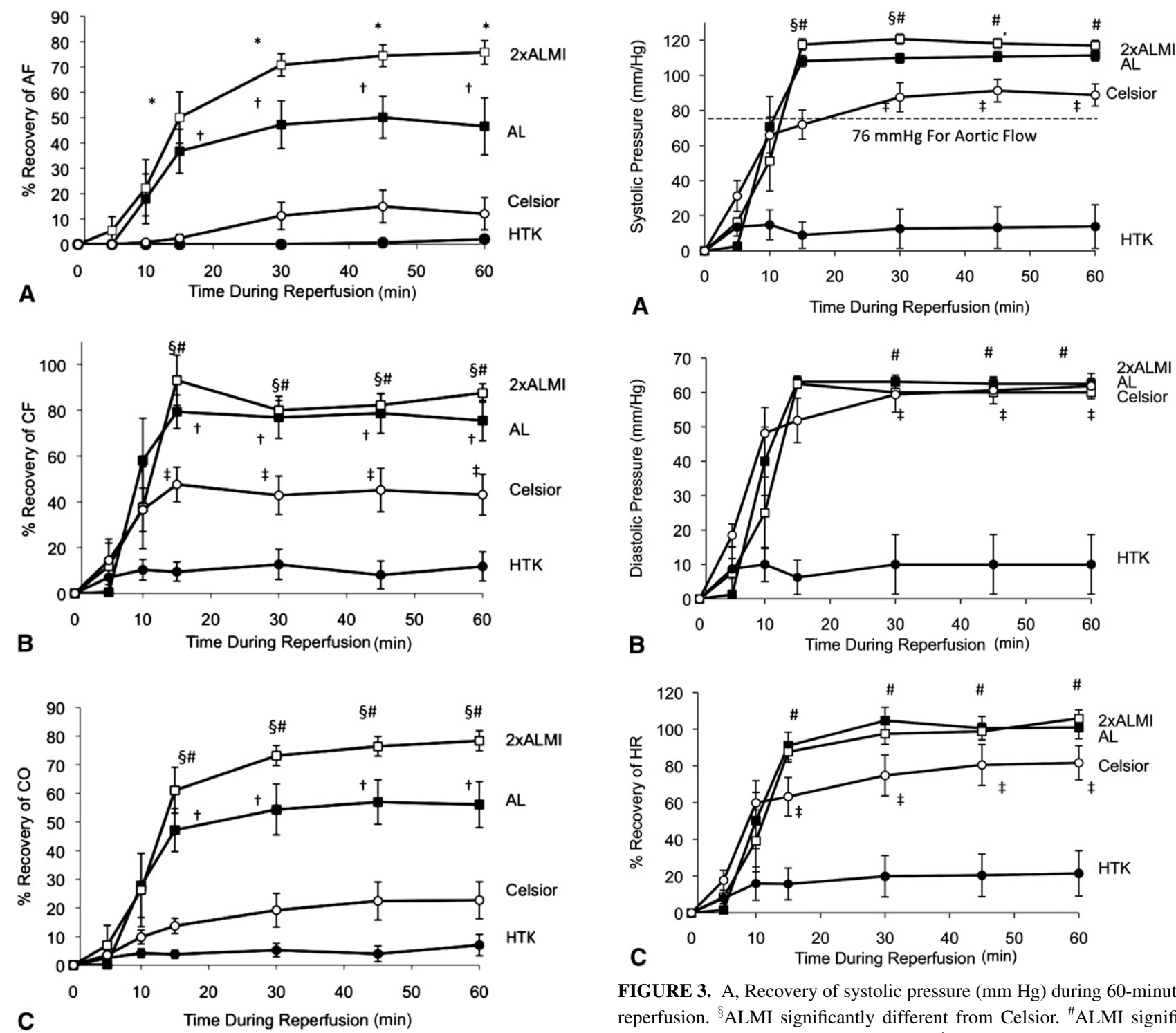

FIGURE 3. A, Recovery of systolic pressure $(\mathrm{mm} \mathrm{Hg})$ during 60 -minute reperfusion. ${ }^{\S}$ ALMI significantly different from Celsior. "ALMI significantly different from Custodiol-HTK. ${ }^{\ddagger}$ Celsior significantly different from Custodiol-HTK. B, Recovery of diastolic pressure $(\mathrm{mm} \mathrm{Hg}$ ) during 60-minute reperfusion. ${ }^{\#}$ Celsior significantly different from CustodiolHTK. ${ }^{\ddagger}$ Celsior significantly different from Custodiol-HTK. C, Percentage recovery of heart rate $(\%)$ during 60 -minute reperfusion in working mode immediately after 5 minutes of oxygenated reperfusion in Langendorff mode. The 4 groups were (1) AL low $\mathrm{Ca}^{2+} / \mathrm{high} \mathrm{Mg}^{2+}$ (ם), (2) $2 \times$ ALMI ( $\square$ ), (3) Custodiol-HTK (๑), and (4) Celsior ( $\bigcirc$ ). Significance $(P<.05)$ was as follows: \#ALMI significantly different from CustodiolHTK. ${ }^{\ddagger}$ Celsior significantly different from Custodiol-HTK. ALMI, Adenosine, lidocaine, melatonin, and insulin; $A L$, adenosine-lidocaine; HTK, Custodiol histidine-tryptophan-ketoglutarate; $H R$, heart rate.

FIGURE 2. A, Percentage recovery of AF (\%) during 60-minute reperfusion in working mode immediately after 5 minutes of oxygenated reperfusion

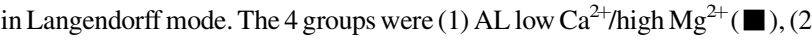
$2 \times$ ALMI ( $\square$ ), (3) Custodiol-HTK $(\bullet)$, and (4) Celsior $(\bigcirc)$. Significance $(P<.05)$ was as follows: $* 2 \times$ ALMI different from all groups. ${ }^{\dagger} \mathrm{AL}$ different from Celsior and Custodiol-HTK. B, Percentage recovery of coronary flow (\%) during 60-minute reperfusion (see A). ${ }^{\S} \mathrm{ALMI}$ significantly different from Celsior. "ALMI significantly different from Custodiol-HTK only. ${ }^{\dagger} \mathrm{AL}$ significantly different from Custodiol-HTK or Celsior. ${ }^{\ddagger}$ Celsior significantly different from Custodiol-HTK. C, Percentage recovery of $\mathrm{CO}(\%)$ during 60 minute reperfusion (see A). ${ }^{\S} \mathrm{ALMI}$ significantly different from Celsior. ${ }^{\#}$ ALMI significantly different from Custodiol-HTK only. ${ }^{\dagger} \mathrm{AL}$ significantly different from Custodiol-HTK or Celsior. $C O$, Cardiac output; $C F$, coronary flow; $A F$, aortic flow; $A L M I$, adenosine, lidocaine, melatonin, and insulin; $A L$, adenosine-lidocaine; $H T K$, Custodiol histidine-tryptophan-ketoglutarate.

$2 \times$ ALMI heart group was the only one that generated AF ( $2 \mathrm{~mL} / \mathrm{min}$ ) (Table 1, Figure 2, A). At 10 minutes, AL and ALMI hearts had spontaneously generated approximately $20 \%$ of their respective baseline AF, whereas CustodiolHTK hearts had zero flow $(0 \%)$ and Celsior hearts had 1 $\mathrm{mL} / \mathrm{min}(\sim 2 \%$ of prearrest). At 30 minutes, $\mathrm{AL}$ and ALMI hearts generated $47 \%$ and $71 \%$ of their prearrest $\mathrm{AF}$ and increased to $50 \%$ and $76 \%$ at 60 minutes 
reperfusion, respectively. In contrast, hearts preserved in Custodiol-HTK generated $0 \%$ and $2 \%$ AF after 30 and 60 minutes, respectively, and Celsior hearts generated $13 \%$ and $17 \%$ prearrest $\mathrm{AF}$ after 30 and 60 minutes, respectively (Table 1, Figure 2, A).

The spontaneous return of $\mathrm{CF}$ at 5 minutes for $\mathrm{AL}, 2 \times$ ALMI hearts, Custodiol-HTK, and Celsior was $1 \%, 9 \%$, $5 \%$, and $14 \%$ of baseline values, respectively, and at 10 minutes $\mathrm{CF}$ increased to $55 \%, 36 \%, 11 \%$, and $38 \%$, respectively (Table 1, Figure 2, B). At 30 minutes reperfusion, the CF increased to $75 \%$ and $48 \%$ for the $\mathrm{AL}$ and Celsior hearts, respectively, whereas the $2 \times$ ALMI hearts increased 2.3 -fold ( $82 \%$ prearrest). At 60 minutes, the return of $\mathrm{CF}$ for AL, $2 \times$ ALMI, and Celsior hearts was $70 \%, 86 \%$, and $48 \%$, respectively. Custodiol-HTK hearts did not increase CF from 10 to 60 minutes and remained at $11 \%$ of prearrest value $\left(2 \mathrm{~mL} / \mathrm{min}^{-1}\right)$ (Table 1, Figure $\left.2, B\right)$.

Recovery of $\mathrm{CO}$ at 5 minutes for all groups in working mode ranged from $1 \%$ to $6 \%$ (Table 1 , Figure $2, C$ ). At 10 minutes, the $\mathrm{CO}$ for AL, $2 \times$ ALMI hearts, CustodiolHTK, and Celsior was $28 \%, 26 \%, 3 \%$, and $11 \%$, respectively. At 30 minutes, the AL and $2 \times$ ALMI hearts doubled and tripled their outputs, respectively, the Celsior hearts doubled their output, and the Custodiol-HTK hearts failed to increase $\mathrm{CO}$ above $3 \%$ of prearrest value (Table 1 , Figure 2, C). At 60 minutes, the AL hearts stabilized CO at $55 \%$ prearrest output, $2 \times$ ALMI hearts increased to $78 \%$, and Celsior increased to $25 \%$ prearrest output. Custodiol-HTK failed to increase $\mathrm{CO}$ over the 60-minute period (Table 1, Figure 2, C). Stroke volume was calculated by dividing $\mathrm{CO}$ by heart rate and ranged from 0.27 to $0.30 \mathrm{~mL}$ beat $^{-1}$ for the 4 groups at baseline (Table 1). At 60 minutes reperfusion, the AL and $2 \times$ ALMI hearts had recovered $55 \%$ and $75 \%$, respectively. In direct contrast, the Custodiol-HTK and Celsior hearts recovered $5 \%$ and $23 \%$ of baseline, respectively.

\section{Recovery of Systolic and Diastolic Developed Pressures}

The systolic and diastolic pressures are shown in Table 1 and Figure 3, $A$ and $B$. Baseline values ranged from 124/60 to $128 / 60 \mathrm{~mm} \mathrm{Hg}$ and were not significantly different. At 5 minutes, the AL and $2 \times$ ALMI hearts generated $2 \%$ and $13 \%$ of baseline pressures, respectively, which rapidly increased to $57 \%$ to $67 \%$ systolic and $40 \%$ to $42 \%$ diastolic at 10 minutes, respectively (Table 1, Figure 3, A, B). At 30 and 60 minutes of reperfusion, the AL and $2 \times$ ALMI hearts had recovered $89 \%$ to $94 \%$ of systolic pressures and $105 \%$ to $100 \%$ of diastolic pressures, respectively. Celsior hearts showed a faster recovery at 5 minutes $(25 \%-32 \%$ baseline) and at 10 minutes had recovered $52 \%$ systolic and $80 \%$ diastolic pressures. At 30 and 60 minutes, Celsior hearts increased systolic pressure to $70 \%$ baseline, but this pressure was not high enough to generate sufficient $\mathrm{AF}$, and the diastolic pressure was $98 \%$ to $100 \%$. Custodiol-HTK failed to increase systolic pressure greater than $14 \mathrm{~mm} \mathrm{Hg}$ (11\% baseline), and diastolic pressure was not greater than $10 \mathrm{~mm} \mathrm{Hg}$ (17\% baseline) over the 60 -minute reperfusion period.

\section{Recovery of Heart Rate and Rate-Pressure Product}

Spontaneous return of heart rate is shown in Table 1 and Figure 3,C. Baseline rates ranged from 275 to 303 beats/ $\min ^{-1}$. At 5 minutes, the AL, $2 \times$ ALMI, and CustodiolHTK hearts had a rate of 4 to 25 beats $/ \mathrm{min}^{-1}$; however, the Celsior hearts had a rate of 48 beats $/ \mathrm{min}^{-1}$. At $10 \mathrm{~min}$ utes, the AL and $2 \times$ ALMI hearts increased their rates to $50 \%$ and $39 \%$ baseline, respectively, and Celsior hearts were beating at $62 \%$ baseline. The Custodiol-HTK hearts increased their heart rate from 22 to 39 beats $/ \mathrm{min}^{-1}$ to 44 beats $/ \mathrm{min}^{-1}(14 \%-16 \%$ baseline $)$ at 10 minutes and did not change during the 60 -minute reperfusion. At $30 \mathrm{~min}$ utes, AL and $2 \times$ ALMI hearts returned $105 \%$ and $97 \%$ of their baseline heart rates, respectively, and Celsior hearts had $75 \%$ of the baseline rate. At 60 minutes, full recovery of heart rate was found in the AL and $2 \times$ ALMI hearts, and $86 \%$ recovery was found in the Celsior hearts.

Baseline RPP ranged from 34,404 to 38,836 beats $/ \mathrm{mm}$ $\mathrm{Hg} / \mathrm{min}^{-1}$ for the 4 preservation groups (Table 1). At $5 \mathrm{~min}$ utes, return of RPP was $0.2 \%$ to $8 \%$ baseline in all groups. At 10 minutes, the $\mathrm{AL}$ and $2 \times \mathrm{ALMI}$ hearts generated $42 \%$ and $34 \%$ of baseline RPP, respectively, and the Celsior hearts generated 39\% (Table 1). The Custodiol-HTK hearts generated $5 \%$ to $10 \%$ baseline RPP during the entire 60 minute reperfusion period. At 30 minutes, the $\mathrm{AL}$ and $2 \times$ ALMI hearts nearly had full recovery of RPP (91\%-93\% return) and $2 \times$ ALMI hearts had $95 \%$ at 60 minutes. The Celsior hearts returned $55 \%$ and $59 \%$ of their RPP at 30 and 60 minutes, respectively.

\section{Maintenance Myocardial Oxygen Consumption in the Last Minute of the 5-Minute Rewarming Phase Before Switching to Working Mode}

At the end of the rewarming phase, the $\mathrm{MVO}_{2}$ for $\mathrm{AL}, 2 \times$ ALMI, Custodiol-HTK, and Celsior hearts in Langendorff mode perfused with their oxygenated arrest solutions was $23.0 \pm 5,20 \pm 4,15 \pm 1$, and $10 \pm 2 \mu \mathrm{mol} \mathrm{O}_{2} / \mathrm{min} / \mathrm{g}$ dry wt, respectively (Figure $4, A$ ). AL and $2 \times$ ALMI hearts were significantly higher than Celsior. The coronary effluent flows in the final minute were $13.7 \pm 0.9$ and $14.2 \pm$ $2.3 \mathrm{~mL}$ for $\mathrm{AL}$ and $2 \times$ ALMI hearts, respectively, and $11.1 \pm 0.9$ and $10.8 \pm 1.4 \mathrm{~mL}$ for Custodiol-HTK and Celsior hearts, respectively.

\section{Lactate and Troponin T Output in the Last Minute of 5-Minute Rewarming}

The lactate outputs for AL, $2 \times$ ALMI, Custodiol-HTK, and Celsior hearts perfused with their oxygenated arrest 

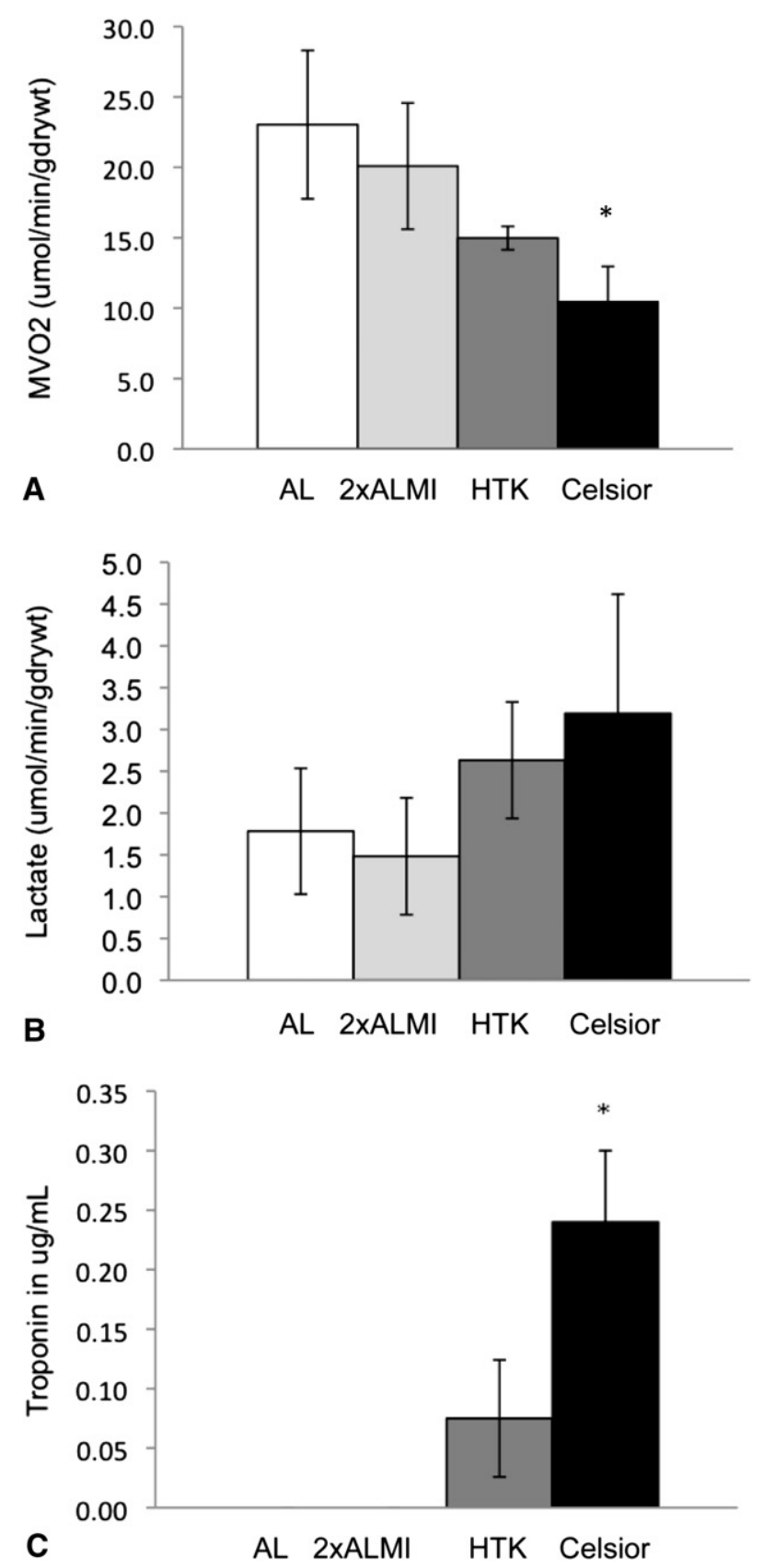

FIGURE 4. $\mathrm{A}, \mathrm{MVO}_{2}$ for the 5 different groups during 5 -minute rewarming period in Langendorff mode and at 10 and 60 minutes reperfusion in working mode. Celsior was significantly different from AL and ALMI $(P<.05)$. B, Lactate output $(\mu \mathrm{mol} / \mathrm{min} / \mathrm{g}$ dry wt heart $)$ measured in the last minute of the 5 -minute rewarming period. Differences were not significant $(P<.05)$. C, Troponin T measured in the last minute of the 5-minute rewarming period. Celsior was significantly different from AL and ALMI $(P<.05) . \quad \mathrm{MVO}_{2}$, Myocardial oxygen consumption; $A L$, adenosinelidocaine; $A L M I$, adenosine, lidocaine, melatonin, and insulin; HTK, Custodiol histidine-tryptophan-ketoglutarate.

solutions were $1.8 \pm 0.8,1.5 \pm 0.7,2.6 \pm 0.7$, and $3.2 \pm 1.4$ $\mu \mathrm{mol}$ lactate $/ \mathrm{min} / \mathrm{g}$ dry $\mathrm{wt}$, respectively (Figure $4, B$ ). No troponin $\mathrm{T}$ was detected in the coronary effluent of $\mathrm{AL}$ or
$2 \times$ ALMI hearts after rewarming (Figure $4, C$ ). In contrast, the troponin T levels for Custodiol-HTK and Celsior hearts were 0.08 and $0.24 \mu \mathrm{g} / \mathrm{mL}$ effluent, respectively.

\section{DISCUSSION}

Over the past 3 decades, the design of organ preservation solutions has been based on 3 fundamental principles: (1) hyperkalemic arrest, (2) a suitable cold, milieu to maintain cell viability during global ischemia, and (3) protection from reperfusion injury. ${ }^{16}$ In 2009, we introduced a new cold and warm normokalemic, polarizing concept to organ preservation, ${ }^{1,8}$ and in 2011 we reported that $\mathrm{AL}$ cardioplegia with $1 \mathrm{mmol} / \mathrm{L} \mathrm{Ca} \mathrm{Ca}^{2+} / 0.5 \mathrm{mmol} / \mathrm{L} \mathrm{Mg}^{2+}$ returned approximately $68 \% \mathrm{CO}, 101 \%$ heart rate, $90 \%$ to $105 \%$ developed pressures, and no detectable troponin $\mathrm{T}(<0.03 \mu \mathrm{g} / \mathrm{mL})$ after 6 hours of cold static storage. The present study showed that further protection is afforded using higher AL levels in the presence of melatonin (100 $\mu \mathrm{mol} / \mathrm{L})$ and insulin $(0.01 \mathrm{IU} / \mathrm{mL})$ added to the $\mathrm{AL}$ preservation solution $(2 \times \mathrm{ALMI})$; the return of $\mathrm{CO}$ increased to $78 \%$ with higher functional recoveries. In contrast and under identical conditions, Custodiol-HTK hearts failed to function with $4 \% \mathrm{CO}, 16 \%$ heart rate, $11 \%$ to $17 \%$ developed pressures, and troponin $\mathrm{T}$ of 0.13 $\mu \mathrm{g} / \mathrm{mL}$. Celsior hearts, despite an $86 \%$ return of heart rate, also failed to return sufficient left ventricular pump function with $25 \% \mathrm{CO}$ and troponin $\mathrm{T}$ of $0.24 \mu \mathrm{g} / \mathrm{mL}$ after rewarming for 8 hours and 5 minutes.

\section{Rewarming (5 Minutes) After Cold Static Storage: Higher Aerobic Maintenance Metabolism and Lower Lactate Efflux in Polarized Adenosine-Lidocaine Hearts}

An interesting outcome from the present study was that the higher functional recoveries in AL hearts were associated with higher (1.5-2-fold) rates of $\mathrm{MVO}_{2}$ in oxygenated, normokalemic, polarized arrested hearts (AL, $2 \times$ ALMI) before switching to working mode compared with hyperkalemic Custodiol-HTK and Celsior arrested hearts (Figure 3, A). Previously, we also reported a higher aerobic maintenance metabolism for AL hearts during 5 minutes of rewarming compared with Celsior hearts after 6 hours of cold static storage (arrested in normal AL with $1.0 \mathrm{mmol} / \mathrm{L}$ $\left.\mathrm{Ca}^{2+} / 0.5 \mathrm{mmol} / \mathrm{L} \mathrm{Mg}^{2+}\right) .{ }^{9}$ The higher $\mathrm{MVO}_{2}$ values in the present study were associated with equivalent decreases in effluent lactate (Figure 3,B), indicating an increased reliance on mitochondrial oxidative phosphorylation to replenish ATP compared with hyperkalemic Custodiol-HTK and Celsior groups. These differences in $\mathrm{MVO}_{2}$ were not due to differences in coronary effluent outflows, which ranged from 11 to $14 \mathrm{~mL} / \mathrm{min}$. The higher troponin $\mathrm{T}$ levels in the hyperkalemic Custodiol-HTK and Celsior groups indicate some myocardial cell damage during 5 minutes of rewarming and reperfusion. Troponin $\mathrm{T}$ was not detected in 
the effluent of the AL or $2 \times$ ALMI hearts (Figure $3, C$ ). A higher $\mathrm{MVO}_{2}$ in $\mathrm{AL}$-arrested hearts may provide a new polarizing protection paradigm for rewarming and implanting donor hearts after cold static storage. ${ }^{9}$

\section{Higher Functional Recoveries in Adenosine- Lidocaine Hearts After 8 Hours of Cold Static Storage}

Adenosine-lidocaine preservation solutions. A standout result of the present study was the spontaneous return of $55 \%$ to $78 \%$ CO after 8 hours of cold ischemic storage with approximately $100 \%$ heart rate and $90 \%$ to $105 \%$ developed pressures for AL and $2 \times$ ALMI hearts. AL preservation encompassed approximately 10 hours of protection from harvest, arrest induction, cold static storage $\left(4^{\circ} \mathrm{C}\right), 5$ minutes of rewarming, to 60 minutes of reperfusion in working mode $\left(38^{\circ} \mathrm{C}\right)$. We previously reported a return of $66 \%$ $\mathrm{CO}$ in rat hearts stored in AL cardioplegia $(1.0 \mathrm{mmol} / \mathrm{L}$ $\mathrm{Ca}^{2+}$ and $0.5 \mathrm{mmol} / \mathrm{L} \mathrm{Mg}^{2+}$ ) after 5 minutes of rewarming after 6 hours of cold static storage. ${ }^{9}$ Improved recovery in the $2 \times$ ALMI hearts may be due to (1) the higher AL concentration exerting a stabilizing effect on membrane polarity, ${ }^{10}$ and thereby reducing damage from $\mathrm{Na}^{+}$and $\mathrm{Ca}^{2+}$ loading during cold storage or rewarming; (2) insulin's effect to possibly facilitate myocardial glucose uptake, ${ }^{17}$ stimulation of nitric oxide production via ischemia-induced myocyte protein kinase C-dependent phosphatidylinositol 3'-kinase-Akt-dependent signaling, and inhibition of superoxide anion $\left(\mathrm{O}_{2}\right)^{12,18}$; and (3) melatonin's cardioprotective properties. Melatonin is a powerful antioxidant and scavenges superoxide radical $\left(\mathrm{O}_{2}^{-}\right)$, hydroxyl radical $\left(\mathrm{OH}^{-}\right)$, and the lipid peroxyl radical. Melatonin prevents the mitochondrial permeability transition pore from opening and collapsing the membrane potential; helps to maintain cardiolipin levels, which constitute approximately $20 \%$ of the total lipid composition of the inner mitochondrial membrane; and has a stabilizing effect on components of the electron transport chain, including preventing the loss of cytochrome c. ${ }^{11}$ The present study did not investigate the relative contributions of $2 \times \mathrm{AL}$, melatonin, or insulin on improved pump function, and further studies are required to tease apart their mechanisms of action in AL preservation and recovery.

In both AL preservation groups, the higher return of left ventricular pump function compared with the CustodiolHTK and Celsior hearts may also have been associated with improved maintenance of cell membrane polarity during all phases of the preservation protocol. ${ }^{1,9}$ The basic electrophysiology behind polarized versus depolarized diastolic arrest is that at "resting" diastolic membrane potentials there are fewer "open" membrane channels, pores, and exchangers compared with depolarized states that can lead to $\mathrm{Na}^{+}$and $\mathrm{Ca}^{2+}$ loading, mitochondrial dysfunction, cell injury, and possibly death. ${ }^{2,7,19}$ The diastolic membrane potential of AL hearts is approximately
$-80 \mathrm{mV}^{2,7}$ By using the Nernstian relation between membrane potential $\left(\mathrm{E}_{\mathrm{m}}\right)$ and extracellular potassium, where $\mathrm{E}_{\mathrm{m}}(\mathrm{mV})=26.23 \ln \left[\mathrm{K}^{+}(\mathrm{mmol} / \mathrm{L})\right]-123.44{ }^{7}$ we predict a membrane potential for Custodiol-HTK hearts of -63 $\mathrm{mV}$ for an extracellular potassium level of $10 \mathrm{mmol} / \mathrm{L} \mathrm{K}^{+}$. Our Nernstian estimate agrees with the direct microelectrode membrane measurement of $-60 \pm 3.6 \mathrm{mV}$ reported by Krohn and colleagues ${ }^{20}$ on sheep cardiac Purkinje fibers bathed in Custodiol-HTK solution. We predict the voltage of the Celsior hearts to be approximately $-50 \mathrm{mV}\left(15 \mathrm{mmol} / \mathrm{L} \mathrm{K}{ }^{+}\right)$.

\section{Celsior Versus Custodiol Histidine-Tryptophan- Ketoglutarate Preservation Solution}

Our finding that Celsior hearts performed better than Custodiol-HTK hearts has been reported in a number of experimental and clinical investigations for solid organ transplantation in heart, ${ }^{21-25}$ lung, ${ }^{26}$ and liver. ${ }^{27}$ Our results are consistent with the rat heart study of Gao and colleagues, ${ }^{28}$ who reported $\mathrm{CO}$ recoveries in Celsior stored hearts of $20 \%$ at 30 minutes after 6 hours and less than $5 \%$ at 30 minutes after 10 hours of cold static storage $\left(2^{\circ} \mathrm{C}-3^{\circ} \mathrm{C}\right)$. In our study, only $10 \%$ of left ventricular function (AF) and $25 \% \mathrm{CO}$ were spontaneously returned after 8 hours of cold storage (Figure 2, $A-C$ ). Celsior has also been reported to be clinically superior to University of Wisconsin (Viaspan; Bristol-Myers Squibb Pharmaceuticals Ltd, Leopardstown, Dublin, Ireland). ${ }^{22,25,29}$ Superior preservation in Celsior is believed to be due to the lower potassium levels $(15 \mathrm{mmol} / \mathrm{L})$, low $\mathrm{Ca}^{2+} /$ high $\mathrm{Mg}^{2+}$, impermeant lactobionate, and potent antioxidant properties of reduced glutathione..$^{21,23,30-33}$ Celsior seems to have been originally designed as a single-solution platform for use during most of the successive steps of the preservation procedure. However, it was not designed as a normokalemic, normothermic reperfusion solution where the heart may be challenged during cold-to-rewarm transitions, as we recently showed in the rat heart after 6 hours of cold static storage. ${ }^{9}$

We were also surprised with the low ventricular outputs from Custodiol-HTK hearts with less than a few percent recovery (Figure 2, A), because they, like Celsior hearts, appeared healthy and soft to touch with no visual signs of ischemia after 8 hours of cold static storage. As with Celsior hearts, the Custodiol-HTK hearts could not generate sufficient left ventricular output against a fixed pressure head, that is, they could not perform adequate physical work (force $\times$ distance) against the $76 \mathrm{~mm} \mathrm{Hg}$ afterload. In 1993, Reichenspurner and colleagues ${ }^{34}$ evaluated Custodiol-HTK for myocardial preservation in cooperation with Eurotransplant and 5 heart transplant centers, and it was concluded that Custodiol-HTK provided good results as long as the ischemic time did not exceed 4 hours. The 5 main features of the Custodiol-HTK solution claimed to be useful for heart preservation are (1) its lower depolarizing extracellular $\mathrm{K}^{+}$, low $\mathrm{Na}^{+}$, low $\mathrm{Ca}^{2+}$ concentrations; (2) the presence of energy substrate alpha-ketoglutarate; 
(3) the presence of antioxidant tryptophan; (4) the presence of mannitol to reduced cell swelling; and (5) a high histidine (198 mmol/L) buffering to counter tissue acidosis during cold global ischemia. ${ }^{20,34}$ In 2010 , Lee and colleagues, ${ }^{35}$ using a rat transplant model, reported superiority of Custodiol-HTK over Celsior on the basis of lower serum creatine kinase levels and less macroscopic deterioration of the graft after 6 or 18 hours of cold storage. However, no pump function was reported, and, as the authors acknowledged, these hearts were not loaded and cannot be extrapolated to clinical conditions. ${ }^{35}$

The overall functional recoveries of hearts after cold static storage in Custodiol-HTK solution reported in the literature vary widely. In 2000 , Saitoh and colleagues ${ }^{36}$ reported a return of $79.9 \% \mathrm{CO}$ after 8 hours of cold static storage $\left(4^{\circ} \mathrm{C}\right)$ compared with $4 \%$ in our study (which was predominately coronary flow) (Figure $2, A-C$ ). Saitoh and colleagues' study had the following differences: (1) male Wistar rats versus male Sprague Dawley rats, (2) lower working afterload $(60 \mathrm{~mm} \mathrm{Hg})$ compared with $76 \mathrm{~mm} \mathrm{Hg}$ in our study, (3) unspecified $\mathrm{Ca}^{2+}$ level in their CustodiolHTK solution (Table 1 in Saitoh and colleagues), (3) 15 minutes of reperfusion in Langendorff mode at unspecified temperatures compared with 5 minutes and $37^{\circ} \mathrm{C}$ in our study, and (4) working mode function for 25 minutes at unspecified temperatures (Figure 1 in Saitoh and colleagues) compared with 60 minutes and $37^{\circ} \mathrm{C}$ in our study. Also in their methods, Saitoh and colleagues state that hearts were reperfused for 20 minutes in Langendorff and $40 \mathrm{~min}$ utes in working mode after cold storage. ${ }^{36}$ These omissions and discrepancies in their methodology make functional comparisons difficult. In 1992, Galinanes and colleagues ${ }^{37}$ reported a return of $22 \% \mathrm{CO}$ in isolated rat hearts stored in Custodiol-HTK for 8 hours $\left(4^{\circ} \mathrm{C}\right)$. In these latter experiments, hearts were subjected to 15 minutes reperfusion followed by 20 minutes working mode. ${ }^{37}$

In our study, the low COs in Custodiol-HTK (and Celsior) hearts after 8 hours may have been due to the shorter 5 -minute rewarming flush period (Figure 1). Warm reperfusion in an oxygenated depolarized state may have promoted unnatural heterogeneous membrane voltage, ionic and metabolic imbalances, and possibly altered lipid membrane organization, such as temperature-dependent phase transitions influencing fluidity, which may have led to suboptimal function after switching to working mode. Nonetheless, we showed that normokalemic, polarizing AL preservation was versatile at both profoundly hypothermic states and during 5-minute cold-to-warm transitions immediately after 8 hours of cold static storage. Functional deficits of Custodiol-HTK hearts may also have arisen from the lack of broad-spectrum antioxidant protection. Schröder and colleagues ${ }^{14}$ recently reported cold-induced mediated oxidant injury in isolated cells after Custodiol-HTK storage, and they have proposed that the addition of iron chelators (or other broad-spectrum antioxidants) to the conventional CustodiolHTK solution may bolster protection. Custodiol-N base solution (modified Custodiol-HTK solution) is now being developed to address some of the concerns with the traditional Custodiol-HTK solution. ${ }^{38}$

\section{Possible Clinical Significance and Future Directions}

The clinical significance of AL preservation solutions exceeding the performance of 2 leading Food and Drug Administration-approved heart preservation solutions Custodiol-HTK and Celsior in isolated rat hearts after 8 hours offers new opportunities. Despite decades of laboratory studies with the reporting of some extraordinary functional recoveries after $6,8,12$, and 24 hours of heart preservation in rat, rabbit, porcine, canine, and sheep models using a myriad of preservation solutions, the clinical reality is that 4 to 5 hours remains the safe period for the human donor heart. Storage time continues to be a critical factor determining the viability of stored solid organs, and extending these times may usher in a new era of organ donation. Longer times may expand the use of organs from marginal beating and non-beating heart donors, and donors may be sought from larger geographic areas, including rural and remote regions. Longer-term 15- to 24-hour preservation times are currently being investigated with AL solutions, as well as constant perfusion studies using isolated pig hearts and kidneys. The possibility also exists that the new polarized arrest and reperfusion paradigm may find utility in preserving other solid organs from a wide patient base, such as lung, liver, and pancreas, or isolated cells, such as stem cells or islet cells.

\section{CONCLUSIONS}

We report that $\mathrm{AL}$ polarized arrest solution with low $\mathrm{Ca}^{2+} / \mathrm{high} \mathrm{Mg}^{2+}(0.22 \mathrm{mmol} / \mathrm{L} / 2.6 \mathrm{mmol} / \mathrm{L})$ returned $55 \%$ $\mathrm{CO}, 101 \%$ heart rate, and $90 \%$ to $105 \%$ developed pressures after 8 hours of cold static storage. When AL was doubled in concentration in the presence of melatonin (100 $\mu \mathrm{mol} / \mathrm{L})$ and insulin $(0.01 \mathrm{IU} / \mathrm{mL})$, the return of $\mathrm{CO}$ increased to $78 \%$ with no detectable troponin $\mathrm{T}(<0.03 \mu \mathrm{g} /$ $\mathrm{mL})$. In contrast, Custodiol-HTK hearts returned $4 \% \mathrm{CO}$, $16 \%$ heart rate, and $11 \%$ to $17 \%$ developed pressures, and troponin $\mathrm{T}$ was $0.13 \mu \mathrm{g} / \mathrm{mL}$ in effluent 5 minutes after the rewarm. Celsior hearts, despite an $86 \%$ return heart rate, also failed to return sufficient left ventricular function $(\sim 10 \%)$ with a return of $25 \% \mathrm{CO}$ and a troponin $\mathrm{T}$ level of $0.24 \mu \mathrm{g} / \mathrm{mL}$.

The authors thank Professor Jakob Vinten-Johansen for comments on the article.

\section{References}

1. Dobson GP. Membrane polarity: a target for myocardial protection and reduced inflammation in adult and pediatric cardiothoracic surgery (editorial - free standing). J Thorac Cardiovasc Surg. 2010;140:1213-7. 
2. Dobson GP, Jones MW. Adenosine and lignocaine: a new concept in nondepolarising surgical arrest, protection and preservation. $J$ Thorac Cardiovasc Surg. 2004;127:794-805.

3. Dobson GP. Organ arrest, protection and preservation: natural hibernation to cardiac surgery: a review. Comp Biochem Physiol Part B. 2004;139:469-85.

4. Corvera JS, Kin H, Dobson GP, Kerendi F, Halkos ME, Katzmark S, et al. Polarized arrest with warm or cold adenosine/lidocaine blood cardioplegia is equivalent to hypothermic potassium blood cardioplegia. J Thorac Cardiovasc Surg. 2005;129:599-606.

5. O'Rullian JJ, Clayson SE, Peragallo R. Excellent outcomes in a case of complex re-do surgery requiring prolonged cardioplegia using a new cardioprotective approach: Adenocaine. J Extra Corpor Technol. 2008;40:203-5.

6. Jin ZX, Zhang SL, Wang XM, Bi SH, Xin M, Zhou JJ, et al. The myocardial protective effects of a moderate potassium adenosine-lidocaine cardioplegia in pediatric cardiac surgery. J Thorac Cardiovasc Surg. 2008;136:1450-5.

7. Sloots K, Dobson GP. Normokalemic adenosine-lidocaine cardioplegia: importance of maintaining a polarized myocardium for optimal arrest and reanimation. J Thorac Cardiovasc Surg. 2010;139:1576-86.

8. Rudd DM, Dobson GP. Towards a new cold and warm non-depolarising, normokalemic arrest paradigm for orthotopic heart transplantation. $J$ Thorac Cardiovasc Surg. 2009;137:198-207.

9. Rudd DM, Dobson GP. Early reperfusion with warm, polarizing adenosinelidocaine cardioplegia improves functional recovery following 6 hours of cold static storage. J Thorac Cardiovasc Surg. 2011;141:1044-55.

10. Makielski JC, Falleroni MJ. Temperature dependence of sodium current block by lidocaine in cardiac Purkinje cells. Am J Physiol. 1991;260(3 Pt 2):H681-9.

11. Petrosillo G, Colantuono G, Moro N, Ruggiero FM, Tiravanti E, Di Venosa N, et al. Melatonin protects against heart ischemia-reperfusion injury by inhibiting mitochondrial permeability transition pore opening. Am J Physiol Heart Circ Physiol. 2009;297:H1487-93.

12. Ji L, Fu F, Zhang L, Liu W, Cai X, Zhang L, et al. Insulin attenuates myocardial ischemia/reperfusion injury via reducing oxidative/nitrative stress. Am J Physiol Endocrinol Metab. 2010;298:E871-80.

13. Ebel D, Preckel B, You A, Müllenheim J, Schlack W, Thämer V. Cardioprotection by sevoflurane against reperfusion injury after cardioplegic arrest in the rat is independent of three types of cardioplegia. Br J Anaesth. 2002;88:828-35.

14. Schröder C, Heintz A, Pexa A, Rauen U, Deussen A. Preclinical evaluation of coronary vascular function after cardioplegia with HTK and different antioxidant additives. Eur J Cardiothorac Surg. 2007;31:821-6.

15. Collinson PO, Boa FG, Gaze DC. Measurement of cardiac troponins. Ann Clin Biochem. 2001;38(Pt 5):423-49.

16. Jahania MS, Sanchez JA, Narayan P, Lasley RD, Mentzer RM. Heart preservation for transplantation: principles and strategies. Ann Thorac Surg. 1999;68:1983-7.

17. Kelly GA, Kirby Orne S. Glucose metabolism in the hypothermic perfused rat heart. Life Sci. 1977;20:597-608.

18. Fischer-Rasokat U, Doenst T. Insulin-induced improvement of postischemic recovery is abolished by inhibition of protein kinase $\mathrm{C}$ in rat heart. J Thorac Cardiovasc Surg. 2003;126:1806-12.

19. Snabaitis AK, Shattock MJ, Chambers DJ. Comparison of polarized and depolarized arrest in the isolated rat heart for long-term preservation. Circulation. 1997; 96:3148-56.

20. Krohn E, Stinner B, Fleckenstein M, Gebhard MM, Bretschneider HJ. The cardioplegic solution HTK: effects on membrane potential, intracellular $\mathrm{K}^{+}$ and $\mathrm{Na}^{+}$activities in sheep cardiac Purkinje fibers. Pflugers Arch. 1989;415: 269-75.

21. Wieselthaler GM, Chevtchik O, Konetschny R, Moidl R, Mallinger R, Mares P, et al. Improved graft function using a new myocardial preservation solution:
Celsior. Preliminary data from a randomized prospective study. Transplant Proc. 1999;31:2067-8

22. Wildhirt SM, Weis M, Schulze C, Conrad N, Rieder G, Enders G, et al. Effects of Celsior and University of Wisconsin preservation solutions on hemodynamics and endothelial function after cardiac transplantation in humans: a singlecenter, prospective, randomized trial. Transpl Int. 2000;13(Suppl 1):S203-11.

23. Vega JD, Ochsner JL, Jeevanandam V, McGiffin DC, McCurry KR, Mentzer JRM, et al. A multicenter, randomized, controlled trial of Celsior for flush and hypothermic storage of cardiac allografts. Ann Thorac Surg. 2001; 71:1442-7.

24. Ackemann J, Gross W, Mory M, Schaefer M, Gebhard M. Celsior versus Custodial: early postischemic recovery after cardioplegia and ischemia at $5^{\circ} \mathrm{C}$. Ann Thorac Surg. 2002;74:522-9.

25. Michel P, Vial R, Rodriguez C, Ferrera R. A comparative study of the most widely used solutions for cardiac graft preservation during hypothermia. J Heart Lung Transplant. 2002;21:1030-9.

26. Warnecke G, Strüber M, Hohlfeld JM, Niedermeyer J, Sommer SP, Haverich A Pulmonary preservation with Bretscheider's HTK and Celsior solution in minipigs. Eur J Cardiothorac Surg. 2002;21:1073-9.

27. Nardo B, Bertelli R, Montalti R, Beltempo P, Puviani L, Pacilè V, et al. Preliminary results of a clinical randomized study comparing Celsior and HTK solutions in liver preservation for transplantation. Transplant Proc. 2005;37:320-2.

28. Gao L, Hicks M, MacDonald PS. Improved preservation of the rat heart with Celsior solution supplemented with cariporide plus glyceryl trinitrate. Am J Transplant. 2005;5:1820-6.

29. Kajihara N, Morita S, Tanoue Y, Boku N, Eto M, Nishida T, et al. The UW solution has greater potential for longer preservation periods than the Celsior solution: comparative study for ventricular and coronary endothelial function after 24-h heart preservation. Eur J Cardiothorac Surg. 2006;29:784-9.

30. Menasche P, Termingnon JL, Pradier F, Grousset C, Mouas C, Alberici G, et al Experimental evaluation of Celsior, a new heart preservation solution. Eur J Cardiothorac Surg. 1994;8:207-13.

31. De Santo LS, Amarelli C, Romano G, Corte AD, Maiello C, Giannolo B, et al. High-risk heart grafts: effective preservation with Celsior solution. Heart Vessels. 2006;21:8-94.

32. Remadi JP, Baron O, Roussel JC, Al HO, Treilhaud M, Despins P, et al. Myocardial preservation using Celsior solution in cardiac transplantation: early results and 5-year follow-up of a multicenter prospective study of 70 cardiac transplantations. Ann Thorac Surg. 2002;73:1495-9.

33. Garlicki M. May preservation solution affect the incidence of graft vasculopathy in transplanted heart? Ann Transplant. 2003;8:19-24.

34. Reichenspurner H, Russ C, Uberfuhr P, Nollert G, Schlüter A, Reichart B, et al. Myocardial preservation using HTK solution for heart transplantation. A multicenter study. Eur J Cardiothorac Surg. 1993;7:414-9.

35. Lee S, Huang CS, Kawamura T, Shigemura N, Stolz DB, Billiar TR, et al. Superior myocardial preservation with HTK solution over Celsior in rat hearts with prolonged cold ischemia. Surgery. 2010;148:463-73. Epub 2010 Jun 2012.

36. Saitoh Y, Hashimoto M, Ku K, Kin S, Nosaka S, Masumura S, et al. Heart preservation in HTK solution: role of coronary vasculature in recovery of cardiac function. Ann Thorac Surg. 2000;69:107-12.

37. Galinanes M, Murashita T, Hearse DJ. Long-term hypothermic storage of the mammalian heart for transplantation: a comparison of three cardioplegic solutions. J Heart Lung Transplant. 1992;11(4 Pt 1):624-35.

38. Loganathan S, Radovits T, Hirschberg K, Korkmaz S, Koch A, Karck M, et al Effects of Custodiol-N, a novel organ preservation solution, on ischemia/reperfusion injury. J Thorac Cardiovasc Surg. 2010;139:1048-56. Epub 2009 Nov 1027. 